\title{
National Car Development in Indonesia with Multiplicative Analytic Hierarchy Process
}

\author{
Abdun Wijaya \\ Master of Information System \\ Diponegoro University \\ Semarang, Indonesia
}

\author{
Catur Edi Widodo \\ Departement Of Physics \\ Diponegoro University \\ Semarang, Indonesia
}

\author{
Rizal Isnanto \\ Departement Of Computer System \\ Diponegoro University \\ Semarang, Indonesia
}

\begin{abstract}
Indonesia's economic growth causes people's purchasing power and the need for vehicles to ease performance is increasing. So the necessary development of national vehicles that can be used in accordance with the needs of society in Indonesia. To produce vehicles in accordance with the needs of the community, it is necessary to analyze the needs of vehicle characteristics in accordance with the characteristics of the society in Indonesia. In this research used seven characteristics of vehicle and method Multiplicative Analytic Hierarchy Process (MAHP). The MAHP model is used to obtain effective and consistent conclusions. Consistency in MAHP model will result in the best vehicle conclusion for national car development in Indonesia.
\end{abstract}

\section{General Terms}

Decision Supporting Systems.

\section{Keywords}

National Car Development, MAHP, Effective and Consistent.

\section{INTRODUCTION}

Given the increasingly complex human activities and the need for transportation tools that facilitate human work, the need for vehicles will continue to increase [1]. One means of public transportation in Indonesia is the car. The Indonesian Automotive Industry Association in 2015 recorded a considerable increase in car sales in Indonesia. The growth of car sales in 2010-2014 reached 57\%. The number of passenger cars until 2014 is $12,497,072$ units [2]. Indonesia's economic growth increases people's purchasing power and vehicle needs to alleviate human work. The impact is increasing productivity, moving goods and services faster. With the increase in revenues from the tax sector will have an impact on sustainable development. Sustainable development will improve the positive investment climate. With a positive domestic investment climate, people's welfare will increase with the opening of new companies and the availability of job vacancies. The potential of the domestic market is large and the need for vehicles is so great that it needs the development of vehicles that can be used according to the needs of the people in Indonesia. This is in line with government programs in creating and improving productivity and competitiveness in international markets.

Choosing the type of car is decision making with multicriteria and multi-objective. The method that can be used to solve multi-criteria problems is the MAHP Method. The advantages of MAHP methods compared to other methods are the ability to overcome multi-criteria and multi-objective problems [3]. The fundamental difference that exists between the classical AHP model by Saaty and the AHP Multiplicative model by Barzilai is how to combine criteria and alternatives in modeling based on available data [4].

Choosing a vehicle MPV as a research object is a conclusion of private vehicle users in the streets of Indonesia is dominated by the type of MPV vehicles from various manufacturers. Almost all families in Indonesia choose multifunction vehicles. MPV vehicles are generally used as private vehicles and vehicles to transport small items that do not require a large area. With the design of the vehicle is quite spacious and comfortable seats for transportation of family members then make most families in Indonesia choose MPV as a personal vehicle. In addition, the type of MPV vehicle fits perfectly with the street characteristic in Indonesia that is not so wide and mostly flat road with a bit of hilly. The large potential of the domestic MPV market causes the need for the development of national car type MPV in the country.

Research on the characteristics of vehicles has been carried out by previous researchers including the Estimation and Use of Dynamic Transmission Models of Automobile Ownership [5], A nested logit model of automobile holdings for one vehicle households [6], A dynamic empirical analysis of household vehicle ownership and utilization [7], Joint mixed logit models of stated and revealed preferences for alternativefuel vehicles [8]. From the previous study the choice of vehicle types can be deduced that most of the options of existing vehicle types examine the characteristics of the vehicle (eg, purchasing and operating costs, and power generated), household characteristics (eg, household structure and income), and owner characteristics (eg gender and age) as factors affecting the behavior of purchasing motor vehicles [1].

The differences and objectives of this study compared with previous studies that have been conducted are the use of seven characteristics of vehicles used in choosing private vehicles and the use of Multiplicative AHP models to generate the best vehicle conclusions for the development of MPV national cars in Indonesia.

\section{RESEARCH METHODOLOGY}

\subsection{Multiplicative Hierarchy Process}

The MAHP method is included in the Multi-Criteria Decision Making Method (MCDM) [9]. The basic problem of MCDM in most outcomes is a competing alternative based on several conflicting criteria. Analytic Hierarchy Process (AHP) is a tool that generates broad multicriteria that uses concepts that can be used to process results and available alternative sequences [10]. Although AHP has a strong ability to handle common problems, AHP has limitations in terms of consistency in outcomes [11]. The MAHP method can be used to solve consistency in the AHP Method [12]-[14]. MAHP 
also accommodates $\lambda$ to reduce extreme judgments. Thus the MAHP Method can be used to determine unbalanced and too flashy values.

The following is a simple MAHP model integrated with existing [3].

$$
v_{i}=c \prod_{k} w_{i k}^{\beta_{k}}
$$

With $v_{i}$ is the alternative value $i, c$ is the criterion, $w_{i k}$ is the alternative weight $i, k$ criterion, and $\beta_{k}$ is the relative importance weight of criteria $k$. Further modeling involving multiple levels of criteria can use the following model.

$$
v_{i}=\prod_{k}\left(v_{i}^{k}\right)^{\beta_{k}}
$$

With $v_{i}$ is an alternative value $i, v_{i}^{k}$ is an alternative value of $i$ criterion $k$, and $\beta_{k}$ is the relative importance weight of criterion $k$. To find $\beta$ can be calculated by using the following equation.

$$
\beta_{k}=\lambda w_{k}
$$

With $\beta_{k}$ is the relative importance weight $k, \lambda$ is the relative weight of the criterion, and $w_{k}$ is the criterion weight.

Stages used in this study using the stages of MAHP. The stages used to generate the following $v_{i}$ values [3] :

1. Establish the relative importance weight of each criterion $w_{k}$.

2. Determine the pairwise pairs of $A_{i j k}$ against $C_{k}$. Where $a_{i j k}=a_{i k} / a_{j k}$. Combine into the matrix $\mathrm{A}=\left\{a_{i j k}\right\}$ to calculate the weight of the $w_{i k}$ ocal criterion for each $i$, $k$.

3. Set the change value $\lambda$ and calculate the value of $\beta_{k}=$ $\lambda w_{k}$.

4. Determine the value of $v_{i}$ based on the equation (1).

From the stage of MAHP will get a model that is hierarchical. The model obtained is a pairwise comparison of criteria and alternatives that are consistent and effective. The results from the model are then combined to produce value comprehensively.

\section{RESEARCH DESIGN}

\subsection{Material and Tools}

The research material used in this research is seven characteristic of the vehicle according to vehicle characteristic stated [1], society generally uses seven characteristics of the vehicle in choosing a private vehicle that is cost, engine capacity, fuel efficiency, wide car, security, seat, and the availability of spare parts.

The tool used for data collection of this research is by using questionnaire. Questionnaires will be divided into several structured questions. The questionnaire can be seen in Table 1. Research data obtained from the brochure and the results of the questionnaires distributed to the community. Questionnaire data on vehicle characteristics will be taken in some cities in Indonesia. The method used in sampling is Slovin method with error tolerance limit of $10 \%$. The results of this questionnaire can reflect the characteristics of the population or people of Indonesia in choosing private vehicles. MPV vehicle data used as the best MPV vehicle model obtained from brochures and interviews. Furthermore, this research can be used developers and government as a reference in developing vehicles that fit the needs of people in Indonesia.

\subsection{Research Procedure}

The procedure of this study is shown in Figure 1 as follows:

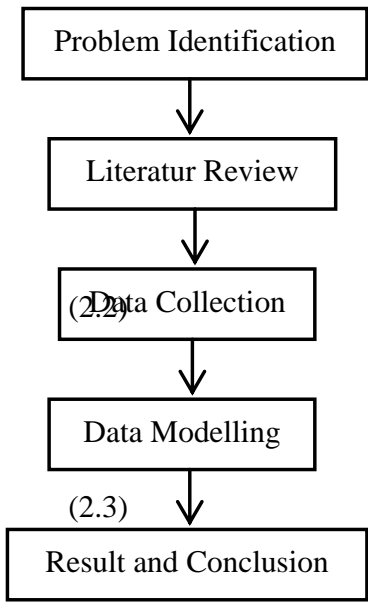

Fig 1. Research procedure

\section{DATA COLLECTION}

\subsection{Sampling Selection}

In the last six years, the oil and gas regulatory body has stated that $68.72 \%$ of the demand for vehicles is dominated by communities in Java [2]. So the sample research will be conducted in Java, especially the capital city of Jakarta, West Java, Central Java and East Java.

\subsection{Characteristic Respondent}

The results of the research data can be seen in Table 2 . Research data will illustrate three number of respondents ie time, gender and occupation.

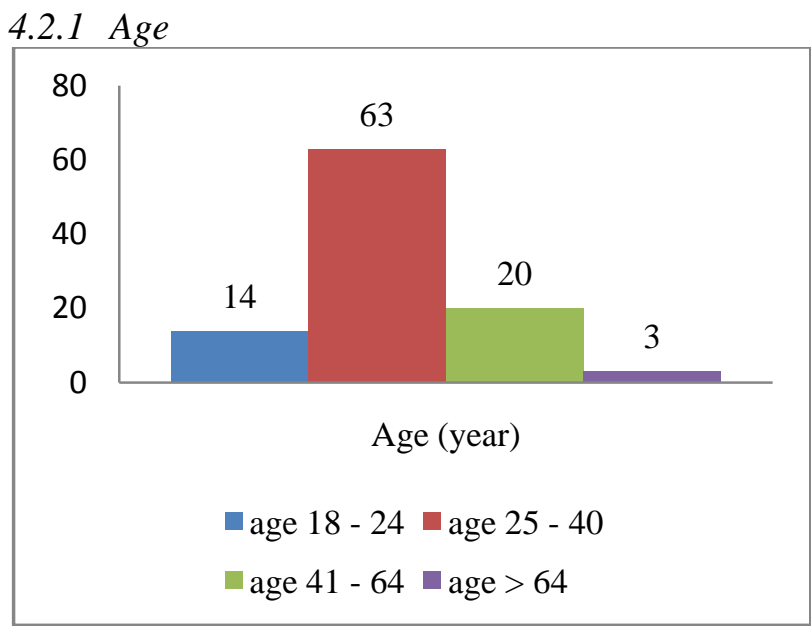

Fig 2. Age of questionnaire respondent

Based on Figure 2, it can be concluded that most of the respondents who were sampled in this study aged between 25 to 40 years 63 percent. While as many as 20 percent of respondents aged 41 to 64 years and 14 percent of respondents aged 18 to 24 years. Only 3 percent of respondents aged over 64 years. 


\subsubsection{Gender}

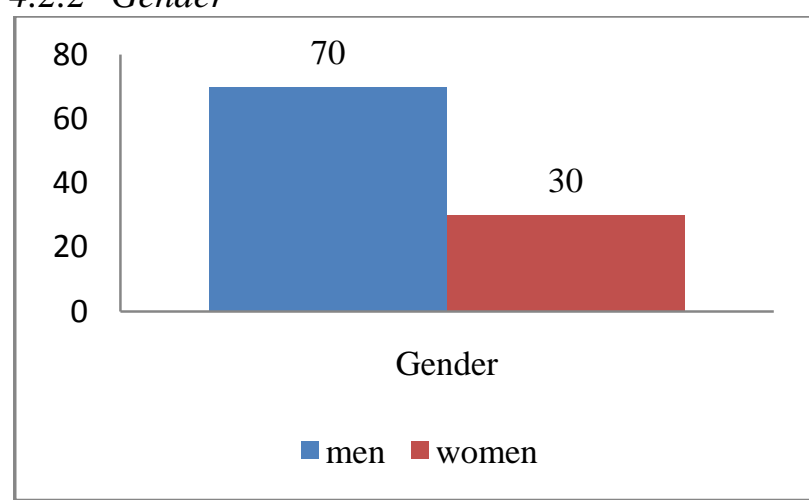

Fig 3. Gender ofquestionnaire respondent

Based on Figure 3. based on the gender of respondents can be concluded that most of the respondents who were sampled in this study male gender as much as 70 percent of the total respondents. The remaining 30 percent of the total sample of the female.

\subsubsection{Work}

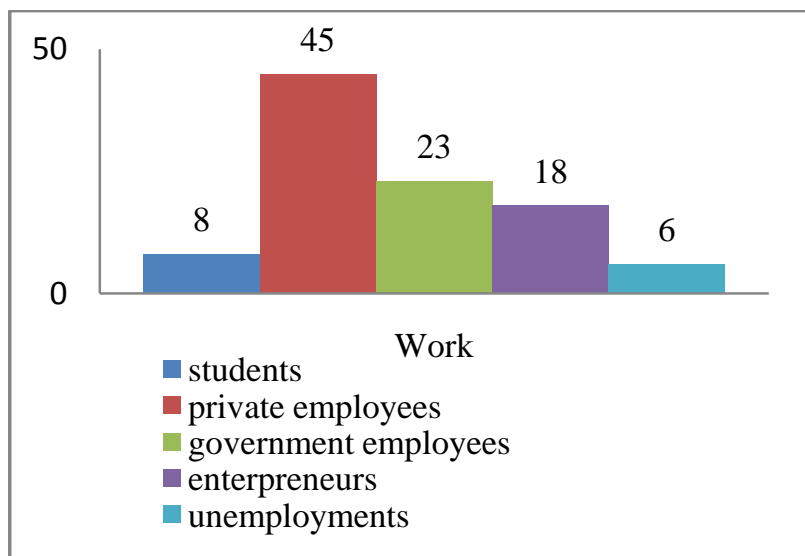

Fig 4. Occupation of questionnaire respondent

Based on Figure 4, it can be concluded that most of the respondents who were sampled in this study had a job as a private employee of 45 percent of the total respondents. As many as 23 percent of respondents work as civil servants and 18 percent of respondents work as entrepreneurs or as entrepreneurs. Only 6 percent of the respondents are unemploymeents and 8 percent still have higher education.

\section{RESULT}

\subsection{Vehicle Model Development}

The vehicle model developed is a type of MPV adapted to the characteristics of the needs of the Indonesian people based on seven characteristics of the vehicle.

\subsubsection{Cost}

In this section, 70 percent of respondents stated that it has cost more than 100 million rupiah to buy a car and 52 percent of them stated that the ease of the vehicle credit facility makes added value in the eyes of the prospective buyer. Thus it can be concluded that Indonesia's economic growth will continue to grow in line with the growing ability of purchasing power of Indonesian society.

\subsubsection{Engine Capacity}

Determine the type of car and engine capacity as part of determining the car. In fact, cars with large engine capacity still remain the choice of the people of Indonesia, as many as 86 percent of respondents chose a vehicle with a capacity of more than 1000cc. 65 percent of Indonesians chose vehicles with Dual Overhead Camshaft (DOHC) engines with 72 percent choosing VVT-i technology. With the ability to produce more power and stable. Thus it can be concluded that most of the people of Indonesia prefer the parties that have a great thrust.

\subsubsection{Fuel Efficiency}

Based on the survey results, 96 percent of respondents want an efficient and environmentally friendly vehicle where the indicator used is the use of fuel vehicles to a minimum without reducing the ability of the vehicle as a whole. One technology used to improve efficiency in fuel use is injection. 82 percent of respondents chose a vehicle using injection technology and 84 percent of respondents chose a vehicle with a tank capacity of vehicle more than 40 liters. It can be concluded that respondents want a vehicle that has a large engine capacity without having to sacrifice efficiency and environmentally friendly aspects.

\subsubsection{Security}

Security elements are important in the design of a vehicle. 98 percent of respondents said that vehicle safety and material is a priority in choosing vehicles and vehicle constituents are part of consideration in choosing a family-friendly fourwheeled vehicle.

\subsubsection{Wide Car}

The width of the vehicle will affect the comfort level of passengers in the car. 80 percent of respondents chose the type of vehicle that has three rows of seats in the vehicle and 64 percent of them chose to have two seats in each row. 98 percent of respondents chose vehicles that have large luggage. Can be concluded that the luggage area will affect the amount of goods that can be brought in the car, the more extensive the baggage then the goods that can be brought into the car will be more.

\subsubsection{Seats}

The seating material will affect the comfort level of the passengers while they are in the car. In accordance with the results of the survey, 92 percent of respondents chose vehicles based on the material seats and 74 percent of other considerations in choosing a vehicle is the height and breadth of the seat. 84 percent of respondents want a control position of the front seat or backward in the car, it makes the chair can be changed position forward or backward. The presence of supporting facilities (garbage cans, where to put drinking water, and electrical resources) around the seats is an added value for 86 percent of respondents, thus the passengers will be more comfortable while in the car.

\subsubsection{Service and Spare Part}

The availability of spare parts in the market will have an impact on vehicle operations, quality and number of spare parts the vehicle will attract someone to buy the vehicle. 98 percent of respondents chose a vehicle based on the quality and availability of official parts. 90 percent of them consider the high selling price of official spare parts of vehicles and 84 percent of respondents among them choose a vehicle that has a sustainable after-sales service. It is felt very helpful owner to always know the best conditions of the vehicle he has. The after-sales service in question is information on periodic service and information about purchased vehicles. The existence of a 24-hour crane facility is the expected value of 
74 percent of respondents. Maintaining the condition of the vehicle to remain in the best condition when used is the thing that must be done by the manufacturer in an effort to provide the best service to its loyal customers.

\subsection{MAHP}

The data used are the characteristics of MPV vehicles in Indonesia. The sample of MPV used in the study can be seen in Table 3. The problems in this study are limited to one level of hierarchy. Dataset used based on brochures and interviews. The model used is a structured hierarchical model. In the uppermost hierarchy layer is the expected conclusion, the best MPV vehicle in Indonesia. In the second layer is a criterion used in selecting MPV vehicles and the bottom layer in the hierarchy is an alternative choice of available MPV vehicles. Implementation of MAHP model in this research can be seen as in Figure 5.

Table 4. Dataset Alternative and Criteria

\begin{tabular}{|l|l|l|l|l|l|l|l|}
\hline & C1 & C2 & C3 & C4 & C5 & C6 & C7 \\
\hline A1 & 190 & 1.400 & 0 & 7 & 6 & 12,18 & 281 \\
\hline A2 & 221,3 & 1.496 & 0 & 7 & 4 & 11,79 & 298 \\
\hline A3 & 213,5 & 1.496 & 0 & 6 & 5 & 11,83 & 170 \\
\hline A4 & 185,75 & 1.329 & 0 & 7 & 6 & 11,65 & 232 \\
\hline A5 & 208,55 & 1.499 & 0 & 7 & 8 & 13,31 & 112 \\
\hline A6 & 133,99 & 1.198 & 0 & 7 & 6 & 9,73 & 121 \\
\hline
\end{tabular}

From Table 4 above it is concluded that there are six alternatives and seven criteria used to determine the best vehicle model. Next, do a direct comparison using the equation $a_{i j k}=a_{i k} / a_{j k}$. The comparison results can be seen in Table 5.

The result of the calculation will be combined so as to produce Aijk pairwise comparison matrix. The results can be seen in Table 6

Table 6. Pairwise Comparison Matrix

\begin{tabular}{|l|l|l|l|l|l|l|}
\hline & $\mathbf{A 1}$ & $\mathbf{A 2}$ & $\mathbf{A 3}$ & $\mathbf{A 4}$ & $\mathbf{A 5}$ & $\mathbf{A 6}$ \\
\hline $\mathbf{A 1}$ & 1,000 & 1,026 & 1,119 & 1,053 & 1,119 & 1,246 \\
\hline $\mathbf{A 2}$ & 0,974 & 1,000 & 1,089 & 1,026 & 1,030 & 1,253 \\
\hline $\mathbf{A 3}$ & 0,894 & 0,918 & 1,000 & 0,940 & 0,951 & 1,157 \\
\hline $\mathbf{A 4}$ & 0,950 & 0,975 & 1,064 & 1,000 & 1,007 & 1,230 \\
\hline $\mathbf{A 5}$ & 0,893 & 0,971 & 1,051 & 0,993 & 1,000 & 1,218 \\
\hline $\mathbf{A 6}$ & 0,803 & 0,798 & 0,864 & 0,813 & 0,821 & 1,000 \\
\hline$\sum \mathbf{A}_{\mathbf{i}}$ & 5,514 & 5,688 & 6,187 & 5,825 & 5,929 & 7,104 \\
\hline
\end{tabular}

Next, do the normalization matrix. Normalization is done to determine the average value of an alternative to other alternatives. The results of normalization can be seen in Table 7.

Table 7. Normalization of pairwise comparison matrix

\begin{tabular}{|l|l|l|l|l|l|l|}
\hline & A1 & A2 & A3 & A4 & A5 & A6 \\
\hline A1 & 0,181 & 0,180 & 0,181 & 0,181 & 0,189 & 0,175 \\
\hline A2 & 0,177 & 0,176 & 0,176 & 0,176 & 0,174 & 0,176 \\
\hline
\end{tabular}

\begin{tabular}{|l|l|l|l|l|l|l|}
\hline A3 & 0,162 & 0,161 & 0,162 & 0,161 & 0,160 & 0,163 \\
\hline $\mathbf{A 4}$ & 0,172 & 0,171 & 0,172 & 0,172 & 0,170 & 0,173 \\
\hline $\mathbf{A 5}$ & 0,162 & 0,171 & 0,170 & 0,170 & 0,169 & 0,171 \\
\hline $\mathbf{A 6}$ & 0,146 & 0,140 & 0,140 & 0,140 & 0,139 & 0,141 \\
\hline$\sum \mathbf{A}_{\mathbf{i}}$ & 1,000 & 1,000 & 1,000 & 1,000 & 1,000 & 1,000 \\
\hline
\end{tabular}

To understand the advantages of MAHP model in overcoming the extreme distance and the effectiveness of the multiplicative model method it will be given $\lambda=0.5, \lambda=1$, and $\lambda=1.5$. So the results obtained as shown in Table 8 .

Table 8. Result MAHP with six alternative

\begin{tabular}{|l|l|l|l|}
\hline & $\boldsymbol{\lambda}=\mathbf{0 . 5} \mathbf{v}_{\mathbf{i}}$ & $\boldsymbol{\lambda}=\mathbf{1} \mathbf{v}_{\mathbf{i}}$ & $\boldsymbol{\lambda}=\mathbf{1 . 5} \mathbf{v}_{\mathbf{i}}$ \\
\hline $\mathbf{A 1}$ & 0,174 & 0,181 & 0,189 \\
\hline $\mathbf{A 2}$ & 0,171 & 0,176 & 0,181 \\
\hline $\mathbf{A 3}$ & 0,164 & 0,162 & 0,159 \\
\hline $\mathbf{A 4}$ & 0,169 & 0,172 & 0,174 \\
\hline $\mathbf{A 5}$ & 0,168 & 0,169 & 0,170 \\
\hline A6 & 0,153 & 0,141 & 0,129 \\
\hline
\end{tabular}

From the table above can be concluded that the model of MPV vehicle that has the highest value is $\mathrm{A} 1$ and become the best in Indonesia. This is because the value of A1 is greater than the other available alternatives. The results of this calculation must have been consistent because the dataset used is the actual data and not using the scale. This is contrary to the classical AHP model where it is required to calculate the consistency level of the dataset used, if the scale does not represent the dataset correctly then the result obtained is not appropriate. The presence of $\lambda$ in MAHP affects the final result. The existence of the difference in value that is too far can be reduced by decreasing the value $\lambda$ so that the results obtained maximum and logical. Conversely, if the difference of vi value of each available alternative is too small then the value of $\lambda$ can be increased to reinforce the difference of each available alternative.

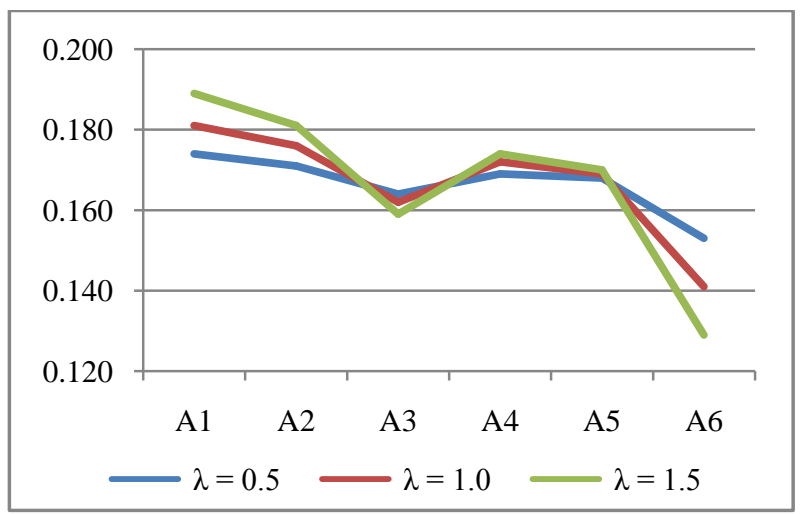

Figure 6. Chart of result MAHP with six alternative

In the graph can be seen the change result of the reduction and addition of value $\lambda$. The existence of the value $\lambda$ to reduce and reinforce the differences between each available alternative.

The MAHP method also overcomes the consistency that exists in classical AHP by comparing two methods directly and avoiding data inconsistencies. To prove the consistency that 
existed in MAHP then will be eliminated alternative A6. The results shown in Table 9.

Table 9. Result MAHP with five alternative

\begin{tabular}{|l|l|l|l|}
\hline & $\boldsymbol{\lambda}=\mathbf{0 . 5} \mathbf{v}_{\mathbf{i}}$ & $\boldsymbol{\lambda}=\mathbf{1} \mathbf{v}_{\mathbf{i}}$ & $\boldsymbol{\lambda}=\mathbf{1 . 5} \mathbf{v}_{\mathbf{i}}$ \\
\hline $\mathbf{A 1}$ & 0,206 & 0,212 & 0,219 \\
\hline $\mathbf{A 2}$ & 0,202 & 0,204 & 0,207 \\
\hline $\mathbf{A 3}$ & 0,194 & 0,188 & 0,182 \\
\hline $\mathbf{A 4}$ & 0,200 & 0,199 & 0,199 \\
\hline $\mathbf{A 5}$ & 0,198 & 0,196 & 0,194 \\
\hline
\end{tabular}

In Table 9 above the results of calculations performed using MAHP resulted in the same conclusions in Table 8 . The impact of elimination on $\lambda$ can be seen in Figure 7.

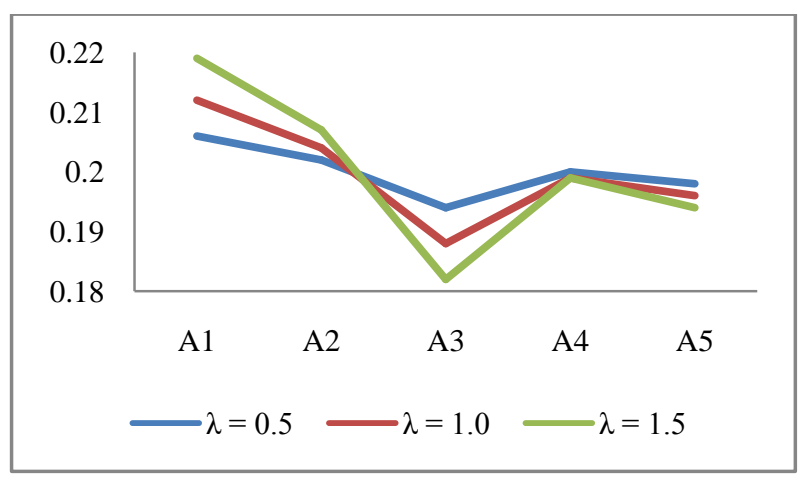

Figure 7. Chart of result MAHP with five alternative

No ranking changes and results are consistent. The inconsistencies that occur in classical AHP are largely due to errors in determining the reach and use of the Saaty rating scale. If there is a change of data then what happens in classic AHP is to change the final value and rank. This can lead to errors in decision making.

\section{CONCLUSION}

The conclusions of this study can be spelled out into three parts, the preferred vehicle characteristics of Indonesian society, the best MPV model, and the effectiveness of MAHP modeling in solving multi-attribute and multi-object decision making problems.

1. Characteristics of vehicles desired by the people of Indonesia in general is a vehicle that has a capacity of engines that are not too large, supported by the capacity of the vehicle tank is not too large and technology that can improve the fuel efficiency of vehicles will be the attraction for prospective customers. The comfortable seat level with seat position control and the availability of other support facilities is important. Luggage area and vehicle compilers are also a concern. With an adequate luggage area and vehicle composition materials that can enhance safety become more valuable. Ease of vehicle loan management should be a means of promotion to attract consumers who have constraints on revenue. Equally important is the availability of vehicle service centers and sustainable after-sales services.

2. Based on the calculation of MAHP with the assessment of the objective attribute then obtained the best MPV vehicle model fell to A1. Value A1 0.181 greater than other alternatives. It can be concluded that based on the seven characteristics of the vehicle and the calculation comprehensively stated that A1 is the best MPV vehicle. So developers and government have a basis and model to conduct the development of MPV vehicles in Indonesia.

3. Modeling MAHP successfully solved the problem of decision making the best MPV vehicle model involving many attributes and many objects. MAHP managed to solve inconsistencies and extreme values resulting in effective and logical decisions. Modeling MAHP can be used in solving various decision-making issues that have many attributes that require consistency and flexibility in data addition and subtraction.

\section{REFERENCES}

[1] G. Baltas and C. Saridakis, "An empirical investigation of the impact of behavioural and psychographic consumer characteristics on car preferences: An integrated model of car type choice," Transp. Res. Part A Policy Pract., vol. 54, pp. 92-110, 2013.

[2] M. Z. Irawan et al., "A market share analysis for hybrid cars in Indonesia," Case Stud. Transp. Policy, 2017.

[3] A. Stam and A. P. Duarte Silva, "On multiplicative priority rating methods for the AHP," Eur. J. Oper. Res., vol. 145, no. 1, pp. 92-108, 2003.

[4] R. Whitaker, "Criticisms of the Analytic Hierarchy Process: Why they often make no sense," Math. Comput. Model., vol. 46, no. 7-8, pp. 948-961, 2007.

[5] I. Hocherman, J. N. Prashker, and M. Ben-Akiva, "Estimation and Use of Dynamic Transaction Models of Automobile Ownership," Transp. Res. Rec., no. 944, pp. 134-141, 1983.

[6] J. Berkovec and J. Rust, "A nested logit model of automobile holdings for one vehicle households," Transp. Res. Part B, vol. 19, no. 4, pp. 275-285, 1985.

[7] F. Mannering and C. Winston, "A Dynamic Empirical Analysis of Household Vehicle Ownership and Utilization," RAND J. Econ., vol. 16, no. 2, p. 215, 1985.

[8] D. Brownstone, D. S. Bunch, and K. Train, "Joint mixed logit models of stated and revealed preferences for alternative-fuel vehicles," Transp. Res. Part B Methodol., vol. 34, no. 5, pp. 315-338, 2000.

[9] F. A. Lootsma, "Scale sensitivity in the multiplicative AHP and SMART," J. Multi-Criteria Decis. Anal., vol. 2, no. 2, pp. 87-110, 1993.

[10] R. W. Saaty, "The analytic hierarchy process-what it is and how it is used," Math. Model., vol. 9, no. 3-5, pp. 161-176, 1987.

[11] P. Ren, Z. Xu, and H. Liao, "Intuitionistic multiplicative analytic hierarchy process in group decision making," Comput. Ind. Eng., vol. 101, no. September, pp. 513524, 2016.

[12] J. Barzilai, W. D. Cook, and B. Golany, "Consistent weights for judgements matrices of the relative importance of alternatives," Oper. Res. Lett., vol. 6, no. 3, pp. 131-134, 1987.

[13] J. Barzilai, "Deriving weights from pairwise comparison matrices," J. Oper. Res. Soc., vol. 48, no. 12, pp. 1226$1232,1997$. 
LIST TABLE

Table 1. Research Questionnaire

\begin{tabular}{|c|c|c|c|}
\hline No. & Question & \multicolumn{2}{|c|}{ Option } \\
\hline \multirow[t]{3}{*}{1.} & \multicolumn{3}{|l|}{ The cost of buying a vehicle } \\
\hline & The cost that you have prepared to buy a car is 100 million & Yes & No \\
\hline & The credit facility & Yes & No \\
\hline \multirow[t]{4}{*}{2.} & \multicolumn{3}{|l|}{ Vehicle engine capacity } \\
\hline & The ideal capacity of the car engine more than $1000 \mathrm{cc}$ & Yes & No \\
\hline & DOHC engine & Yes & No \\
\hline & The VVT-i engine & Yes & No \\
\hline \multirow[t]{4}{*}{3.} & \multicolumn{3}{|l|}{ Fuel efficiency } \\
\hline & The fuel efficiency of the car becomes a major consideration & Yes & No \\
\hline & Injection car & Yes & No \\
\hline & Car fuel tank of more than 40 liters & Yes & No \\
\hline \multirow[t]{2}{*}{4.} & \multicolumn{3}{|l|}{ Vehicle safety } \\
\hline & Vehicle material compilers & Yes & No \\
\hline \multirow[t]{4}{*}{5.} & \multicolumn{3}{|l|}{ Wide car } \\
\hline & The ideal line number of 3 rows of seats & Yes & No \\
\hline & The number of seats in the car in each row of seats 2 pieces of seats & Yes & No \\
\hline & Wide car luggage is important & Yes & No \\
\hline \multirow[t]{5}{*}{6.} & \multicolumn{3}{|l|}{ Material chair } \\
\hline & The constituent material of the chair into consideration & Yes & No \\
\hline & Control seat position & Yes & No \\
\hline & Special chair elderly or child & Yes & No \\
\hline & Support facilities (such as a music player, air conditioning and door lock) & Yes & No \\
\hline \multirow[t]{4}{*}{7.} & \multicolumn{3}{|l|}{ Service and spare part } \\
\hline & Quality of spare parts & Yes & No \\
\hline & The price of the original spare parts & Yes & No \\
\hline & Vehicle post-sale service & Yes & No \\
\hline
\end{tabular}

Table 2. The results of the questionnaire

\begin{tabular}{|l|l|l|l|l|l|l|l|l|}
\hline No. & \multicolumn{2}{|l|}{} & & No. & & \\
\hline 1. & \multicolumn{2}{|l|}{ The cost of buying a vehicle } & 6. & \multicolumn{2}{l|}{ Material chair } \\
\hline & Yes (\%) & No (\%) & Total & & Yes (\%) & No (\%) & Total \\
\hline & 64 & 36 & 100 & & 90 & 10 & 100 \\
\hline & 52 & 48 & 100 & & 82 & 18 & 48 \\
\hline $\mathbf{2 .}$ & Vehicle engine capacity & & & 52 & 6 & 100 \\
\hline & Yes (\%) & No (\%) & Total & & 94 & 100 \\
\hline & 84 & 16 & 100 & $\mathbf{7 .}$ & Service and spare part & \\
\hline & 64 & 36 & 100 & & Yes (\%) & No (\%) & Total \\
\hline
\end{tabular}




\begin{tabular}{|c|c|c|c|c|c|c|}
\hline & 70 & 30 & 100 & 98 & 2 & 100 \\
\hline \multirow[t]{5}{*}{3.} & \multicolumn{3}{|c|}{ Fuel efficiency } & 90 & 10 & 100 \\
\hline & Yes $(\%)$ & No $(\%)$ & Total & 84 & 16 & 100 \\
\hline & 94 & 6 & 100 & & & \\
\hline & 80 & 20 & 100 & & & \\
\hline & 82 & 18 & 100 & & & \\
\hline \multirow[t]{3}{*}{4.} & \multicolumn{3}{|c|}{ Vehicle safety } & & & \\
\hline & Yes (\%) & No $(\%)$ & Total & & & \\
\hline & 100 & 0 & 100 & & & \\
\hline \multirow[t]{5}{*}{5.} & \multicolumn{3}{|c|}{ Wide car } & & & \\
\hline & Yes (\%) & No (\%) & Total & & & \\
\hline & 80 & 20 & 100 & & & \\
\hline & 64 & 36 & 100 & & & \\
\hline & 96 & 4 & 100 & & & \\
\hline
\end{tabular}

Table 3. Sample of MPV car in Indonesia

\begin{tabular}{|c|c|c|c|c|c|c|c|}
\hline & $\begin{array}{l}\text { Cost } \\
\text { (Million IDR ) }\end{array}$ & $\begin{array}{l}\text { Machine } \\
\text { Capacity } \\
\text { ( cc ) }\end{array}$ & $\begin{array}{l}\text { Fuel Efficiency } \\
\text { ( km / liter ) }\end{array}$ & Seats & $\begin{array}{l}\text { Vehicle } \\
\text { Security }\end{array}$ & $\begin{array}{l}\text { Wide Vehicle } \\
(\mathrm{mm})\end{array}$ & $\begin{array}{l}\text { Service and } \\
\text { Spare Parts }\end{array}$ \\
\hline $\begin{array}{l}\text { Suzuki } \\
\text { Ertiga } \\
1.5 \mathrm{GA} \mathrm{M/T}\end{array}$ & 190 & 1.400 & 0 & 7 & $\begin{array}{l}\text { 1. Central } \\
\text { lock } \\
\text { 2. Air bag } \\
\text { 3. Car sensor } \\
\text { 4. Power } \\
\text { window } \\
\text { 5. Crash } \\
\text { sensor } \\
\text { 6. Brake } \\
\text { assist. }\end{array}$ & $\begin{array}{l}4.265 \times 1.695 \\
\times 1.685\end{array}$ & 281 \\
\hline $\begin{array}{l}\text { Toyota } \\
\text { Avanza } \\
1.5 \mathrm{G} \mathrm{M} / \mathrm{T}\end{array}$ & 221,3 & 1.496 & 0 & 7 & $\begin{array}{l}\text { 1. Crash } \\
\text { sensor } \\
\text { 2. Air bag } \\
\text { 3. Car sensor } \\
\text { 4. Power } \\
\text { window. }\end{array}$ & $\begin{array}{l}4.190 \times 1.660 \\
\times 1.695\end{array}$ & 298 \\
\hline $\begin{array}{l}\text { Honda } \\
\text { Mobilio } \\
1.5 \mathrm{E} \mathrm{M/T}\end{array}$ & 213,5 & 1.496 & 0 & 6 & $\begin{array}{ll}\text { 1. } & \text { Crash } \\
\text { sensor } \\
\text { 2. } \text { Central } \\
\text { lock } \\
\text { 3. Air bag } \\
\text { 4. Alarm } \\
\text { mobil } \\
\text { 5. Power } \\
\text { window. }\end{array}$ & $\begin{array}{l}4.386 \times 1.683 \\
\times 1.603\end{array}$ & 170 \\
\hline $\begin{array}{l}\text { Daihatsu } \\
\text { Xenia } \\
1.3 \mathrm{R} \mathrm{M} / \mathrm{T}\end{array}$ & 185,75 & 1.329 & 0 & 7 & $\begin{array}{l}\text { 1. Crash } \\
\text { sensor } \\
\text { 2. Central } \\
\text { lock } \\
\text { 3. Air bag } \\
\text { 4. Car sensor } \\
\text { 5. Power } \\
\text { window } \\
\text { 6. Folding } \\
\text { mirrors }\end{array}$ & $\begin{array}{l}4.140 \times 1.660 \\
\times 1.695\end{array}$ & 232 \\
\hline
\end{tabular}




\begin{tabular}{|c|c|c|c|c|c|c|c|}
\hline $\begin{array}{l}\text { Mitsubishi } \\
\text { Expander } \\
1.5 \mathrm{GLS} \mathrm{M/T}\end{array}$ & 208,55 & 1.499 & 0 & 7 & $\begin{array}{l}\text { 1. Crash } \\
\text { sensor } \\
\text { 2. Central } \\
\text { lock } \\
\text { 3. Air bag } \\
\text { 4. Parking } \\
\text { sensor } \\
\text { 5. Car sensor } \\
\text { 6. Power } \\
\text { window } \\
\text { 7. Folding } \\
\text { mirrors } \\
\text { 8. Brake } \\
\text { assist. }\end{array}$ & $\begin{array}{l}4.475 \times 1.750 \\
\times 1.700\end{array}$ & 112 \\
\hline $\begin{array}{l}\text { Datsun } \\
\text { Go+ } \\
\text { 1.2 T-Style }\end{array}$ & 133,99 & 1.198 & 0 & 7 & $\begin{array}{l}\text { 1. } \text { Crash } \\
\text { sensor } \\
\text { 2. Central } \\
\text { lock } \\
\text { 3. Air bag } \\
\text { 4. Parking } \\
\text { sensor } \\
\text { 5. Car sensor } \\
\text { 6. Power } \\
\text { window. }\end{array}$ & $\begin{array}{l}3.995 \times 1.635 \\
\times 1.490\end{array}$ & 121 \\
\hline
\end{tabular}

(*source April 2018)

Table 5. Direct comparison of seven alternatif criteria

\begin{tabular}{|c|c|c|c|c|c|c|c|c|}
\hline $\begin{array}{l}\text { Perbandingan } \\
\text { Berpasangan }\end{array}$ & $\mathrm{C} 1$ & $\mathrm{C} 2$ & $\mathrm{C} 3$ & $\mathrm{C} 4$ & $\mathrm{C} 5$ & C6 & $\mathrm{C} 7$ & $A_{i j k}$ \\
\hline $\mathrm{A} 1 / \mathrm{A} 2$ & 0,462 & 0,483 & 0,000 & 0,500 & 0,600 & 0,508 & 0,485 & 1,026 \\
\hline $\mathrm{A} 2 / \mathrm{A} 1$ & 0,538 & 0,517 & 0,000 & 0,500 & 0,400 & 0,492 & 0,515 & 0,974 \\
\hline $\mathrm{A} 1 / \mathrm{A} 3$ & 0,471 & 0,483 & 0,000 & 0,538 & 0,545 & 0,507 & 0,623 & 1,119 \\
\hline A3 / A1 & 0,529 & 0,517 & 0,000 & 0,462 & 0,455 & 0,493 & 0,377 & 0,894 \\
\hline $\mathrm{A} 1 / \mathrm{A} 4$ & 0,506 & 0,513 & 0,000 & 0,500 & 0,500 & 0,511 & 0,548 & 1,053 \\
\hline A4 / A1 & 0,494 & 0,487 & 0,000 & 0,500 & 0,500 & 0,489 & 0,452 & 0,950 \\
\hline A1 / A5 & 0,509 & 0,500 & 0,000 & 0,538 & 0,429 & 0,478 & 0,715 & 1,119 \\
\hline A5 / A1 & 0,491 & 0,500 & 0,000 & 0,462 & 0,571 & 0,522 & 0,285 & 0,894 \\
\hline A1 / A6 & 0,544 & 0,530 & 0,000 & 0,500 & 0,500 & 0,556 & 0,699 & 1,245 \\
\hline A6/A1 & 0,456 & 0,470 & 0,000 & 0,500 & 0,500 & 0,444 & 0,301 & 0,803 \\
\hline $\mathrm{A} 2 / \mathrm{A} 3$ & 0,509 & 0,500 & 0,000 & 0,538 & 0,444 & 0,499 & 0,637 & 1,089 \\
\hline A3 / A2 & 0,491 & 0,500 & 0,000 & 0,462 & 0,556 & 0,501 & 0,363 & 0,918 \\
\hline $\mathrm{A} 2$ / A4 & 0,544 & 0,530 & 0,000 & 0,500 & 0,400 & 0,503 & 0,562 & 1,026 \\
\hline A4 / A2 & 0,456 & 0,470 & 0,000 & 0,500 & 0,600 & 0,497 & 0,438 & 0,974 \\
\hline A2 / A5 & 0,515 & 0,499 & 0,000 & 0,500 & 0,333 & 0,470 & 0,727 & 1,030 \\
\hline $\mathrm{A} 5 / \mathrm{A} 2$ & 0,485 & 0,501 & 0,000 & 0,500 & 0,667 & 0,530 & 0,273 & 0,971 \\
\hline A2 / A6 & 0,623 & 0,555 & 0,000 & 0,500 & 0,400 & 0,548 & 0,711 & 1,253 \\
\hline $\mathrm{A} 6 / \mathrm{A} 2$ & 0,377 & 0,445 & 0,000 & 0,500 & 0,600 & 0,452 & 0,289 & 0,798 \\
\hline A3 / A4 & 0,535 & 0,530 & 0,000 & 0,462 & 0,455 & 0,504 & 0,423 & 0,940 \\
\hline A4 / A3 & 0,465 & 0,470 & 0,000 & 0,538 & 0,545 & 0,496 & 0,577 & 1,064 \\
\hline A3 / A5 & 0,506 & 0,499 & 0,000 & 0,462 & 0,385 & 0,471 & 0,603 & 0,951 \\
\hline A5 / A3 & 0,494 & 0,501 & 0,000 & 0,538 & 0,615 & 0,529 & 0,397 & 1,051 \\
\hline A3 / A6 & 0,614 & 0,555 & 0,000 & 0,462 & 0,455 & 0,549 & 0,584 & 1,157 \\
\hline $\mathrm{A} 6 / \mathrm{A} 3$ & 0,386 & 0,445 & 0,000 & 0,538 & 0,545 & 0,451 & 0,416 & 0,864 \\
\hline
\end{tabular}




\begin{tabular}{|l|l|l|l|l|l|l|l|l|}
\hline A4 / A5 & 0,471 & 0,470 & 0,000 & 0,500 & 0,429 & 0,467 & 0,674 & 1,007 \\
\hline A5 / A4 & 0,529 & 0,530 & 0,000 & 0,500 & 0,571 & 0,533 & 0,326 & 0,993 \\
\hline A4 / A6 & 0,581 & 0,526 & 0,000 & 0,500 & 0,500 & 0,545 & 0,657 & 1,230 \\
\hline A6 / A4 & 0,419 & 0,474 & 0,000 & 0,500 & 0,500 & 0,455 & 0,343 & 0,813 \\
\hline A5 / A6 & 0,609 & 0,556 & 0,000 & 0,500 & 0,571 & 0,578 & 0,481 & 1,218 \\
\hline A6 / A5 & 0,391 & 0,444 & 0,000 & 0,500 & 0,429 & 0,422 & 0,519 & 0,821 \\
\hline
\end{tabular}

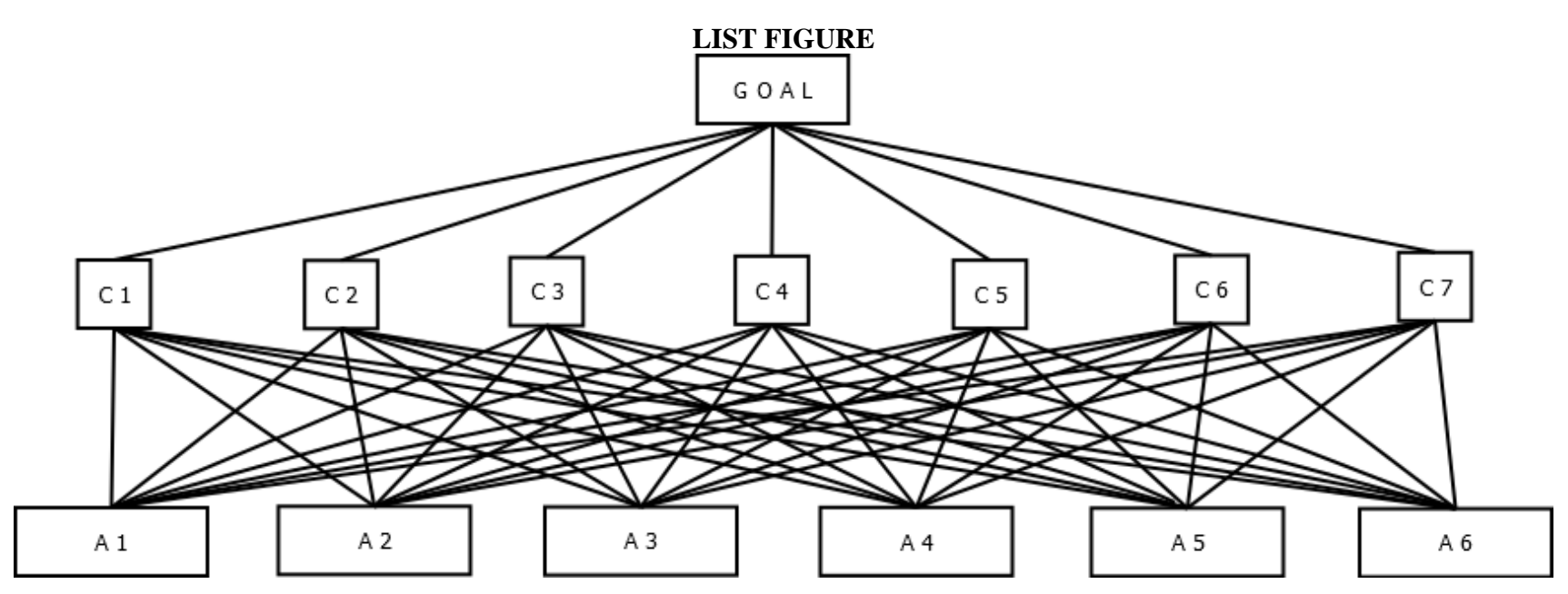

Figure 5. Hierarchy Model 